\title{
Using Group Discussion with Taiwan's EFL College Students: A Comparison of Comprehension Instruction for Book Club, Literature Circles, and Instructional Conversations
}

\author{
Fu-Yuan Shen ${ }^{1}$ \\ ${ }^{1}$ Department of English, National Taitung University, Taiwan \\ Correspondence: Fu-Yuan Shen, Department of English, National Taitung University, Taitung City, Taiwan. Tel: \\ 886-89-517-715. E-mail: fuyuan@nttu.edu.tw
}

Received: September 10, 2013 Accepted: October 1, 2013 Online Published: November 5, 2013

doi:10.5539/elt.v6n12p58 URL: http://dx.doi.org/10.5539/elt.v6n12p58

\begin{abstract}
The research presented here involved a one-semester study; during this period of time, reading comprehension instruction representing three major discussion-centered approaches (Book Club, BC; Literature Circles, LC; Instructional Conversations, IC) was designed and implemented. The effectiveness of the three experimental approaches and one control approach (basal comprehension) were compared. BC and LC are peer-led, small-group discussions, while IC is teacher-led group discussions. The design of the instruction for the control approach was based on the basal reading program used in the participating classroom. Student participants $(N=$ 160) were all EFL college students attending a public university on the eastern coast of Taiwan. Assessments of reading comprehension, including three standardized tests and two essays, were developed to compare students' performance in relation to higher level comprehension. No significant differences were found on one measure of lesson-text understanding, factual comprehension. However, for interpretive comprehension and theme-related essays, the BC, LC, and IC students outperformed the basal control students; occasionally, the BC students scored slightly higher than the LC and IC students did. For the beyond-lesson-text comprehension assessment, there was a modest superior result in favor of the experimental students.
\end{abstract}

Keywords: high-level comprehension, book club, literature circles, instructional conversations, ESL reading

\section{Introduction}

Students' reading proficiency is critical to their academic performance and future career success in light of today's "knowledge economy" world, where information proliferation and technological innovations lead to high demands for literacy in the present and the future (Bransford, Brown, \& Cocking, 1999). There is a pressing call for increasing students' degree of literacy, especially the ability to understand complex text (RAND Reading Study Group, 2002). In other words, students need to move beyond simple, literal understanding of text and achieve high-level comprehension. Higher order comprehension has been defined as the ability to think about text logically, critically, and reflectively (Chang-Wells \& Wells, 1993). Thus, finding effective comprehension instructional approaches is an urgent task in the field of reading research.

The field of reading research has succeeded in identifying discussion-oriented approaches for improving students' reading comprehension (Murphy, Wilkinson, Soter, Hennessey, \& Alexander, 2009; Soter et al., 2008). These instructional approaches center on engaging, interesting, and motivational discussions about a text, including Grand Conversations (Eeds \& Wells, 1989), Book Club (Raphael \& McMahon, 1994), Literature Circles (Short \& Pierce, 1990), Instructional Conversations (Goldenberg, 1993), Questioning the Author (Beck, McKeown, Hamilton, \& Kucan, 1997), the Junior Great Books Discussions (Great Books Foundation, 1987), Collaborative Reasoning (Waggoner, Chinn, Yi, \& Anderson, 1995), Philosophy for Children (Sharp, 1985), and Paideia Seminars (Billings \& Fitzgerald, 2002). Such teaching approaches can be generally categorized as collaborative, text-based discussion, wherein the text-processing activities of clarification, explanation, and interpretation are conducted during and after reading. The characteristics of such discussion-focused approaches include open-ended, student-generated questions, student possession of interpretive authority, and less teacher intervention (e.g., Beck, McKeown, Sandora, Kucan, \& Worthy, 1996; Chinn, O'Donnell, \& Jinks, 2000; McCann, Johannessen, Kahn, \& Flanagan, 2006; Nystrand, Wu, Gamoran, Zeiser, \& Long, 2003). 
Through discussion-based practices, students develop critical, analytic, and reflective thinking about text-embedded ideas (Soter, Wilkinson, Connors, Murphy, \& Shen, 2010; Wilkinson, Soter, \& Murphy, 2010). A considerable number of studies have revealed that quality discussion of text can promote reading comprehension and general learning (Anderson, Chinn, Waggoner, \& Nguyen, 1998; Cazden, 2001; Mercer, 2000; Nystrand, 1997; Wegerif, Mercer, \& Dawes, 1999). Among the discussion-based approaches mentioned above, Book Cub, Literature Circles, and Instructional Conversations have been used with English language learners (ELLs), producing notable effects on their reading comprehension. For one discussion approach, Book Club, four studies showed impressive results, with L2 students demonstrating comprehension gains (Brock, McVee, Shojgreen-Downer, \& Duenas, 1998; Goatley, Brock, \& Raphael, 1995; Kong \& Fitch, 2002; Raphael \& Brock, 1993). For another discussion approach, Literature Circles, several empirical studies have also shown that the use of small-group discussion can enhance English ELLs' reading comprehension (Carrison \& Ernst-Slavit, 2005; Farris, Nelson, \& L'Allier, 2007; Kim, 2004; Martinez-Roldan \& Lopez-Robertson, 1999; Peralta-Nash \& Dutch, 2000). In the case of Instructional Conversations, available evidence supports similar outcomes with ELLs (Echevarria \& McDonough, 1995; Olezza, 1999; Perez, 1996; Saunders \& Goldenberg, 1999; Saunders, Patthey-Chavez, \& Goldenberg, 1997; Todhunter, 2007). The sum total of the studies of the foregoing discussion leaves a consistent picture that discussion-focused approaches are effective with L2 students.

Book Club, Literature Circles, and Instructional Conversations have been widely used in English as L1 and L2 contexts. Although there is a general consensus in the reading community that these discussion-focused approaches enhance L1/L2 students' higher order comprehension, there is surprisingly little evidence attesting to the effectiveness of such instructional approaches, particularly for EFL students' reading comprehension. To date, there is virtually no experimental evidence related to discussion-oriented instruction for the development of Taiwan's EFL college students' reading comprehension skills. Most importantly, the available related studies suffer from a lack of rigorous comparison of the discussion approaches in terms of students' reading performance. Therefore, the design of the study included four classrooms where all students read five stories in common, and comparing results of three discussion-oriented approaches and one control group. Comprehension tests and essays were used as measurements.

The primary goal of this study was to compare and analyze the efficacy of discussion-focused approaches and a control approach. Standardized instruction for representing the abovementioned three major discussion approaches aiming to promote higher order comprehension were designed and implemented. Students' high-level comprehension of common text was investigated under the following instructional approaches: Book Club, Literature Circles, Instructional Conversations, and basal instruction. One experimental approach, Book Club, integrates independent reading, journal writing, teacher instruction, and community share into a complete reading program. Another experimental approach, Literature Circle, includes both teacher's mini-lessons and student-led discussions. The other experimental approach, Instructional Conversation, involves teacher-led discussions and direct teaching of explicit comprehension strategies. The control approach is the traditional basal-comprehension method based largely on the monological instructional pattern. The present study addressed two specific research questions:

1) Are there differences in comprehension of lesson texts among approaches?

2) Are there differences in students' performance of comprehension on nonlesson texts among approaches?

\section{Method}

The present study was designed as a static-group comparison among four classrooms. It relied upon quasi-experimental methods to collect and analyze data to explore the impact of the discussion-based approaches on students' high-level comprehension of literary text.

\subsection{Materials}

Lessons for each of the four approaches were developed, based on five American short stories. Thus, students in all of the approaches read the same texts. These narratives were Ernest Hemingway's "A Day's Wait" and "Hills Like White Elephants", Judy Troy's "Secrets", Amy Tan's “Two Kinds", and William Carlos Williams' "The Use of Force". Each text was the core text in a three-week lesson plan.

\subsection{Lesson Design}

One common format in each experimental approach was teacher-directed, whole-class instruction in which an instructor explained portions of the text in both Chinese and English. For the experimental lessons, the teacher divided the whole class into five groups, each of which was composed of eight heterogeneous students in gender and academic ability. The group members communicated among themselves in either English or Chinese. The 
English-only policy was not observed in this study. The lesson design for preparing, initiating, and guiding group discussion in each experimental approach is discussed in the following sections. The sample lesson plans for each teaching approach are provided in Appendices A-1, A-2, A-3, and A-4.

\subsubsection{Book Club}

The Book Club program consisted of four elements: reading, writing, instruction, and community share. Teacher instruction focused on language conventions, literary elements, and comprehension strategies. After the teacher explained important parts of the lesson text, students were asked to write responses to the text just read. Then group members convened to discuss the text, based on their own response journal. This was a peer-led group discussion, in which students generated questions, controlled the turns taken, and possessed authority for textual interpretation. Walking around the discussion groups, the teacher provided necessary assistance to facilitate the discussion. After the group discussion came the community share time, when the whole class met together again to exchange their insights about the text.

\subsubsection{Literature Circles}

Two central components of Literature Circles were mini-lesson and independent reading. In each class session, the mini-instruction lasted 15 to 20 minutes, during which time a teacher highlighted the thematic significances in the reading assignment, explained complex sentences in the text, and instructed comprehension strategies. After the mini-lesson, group members met together and read the lesson text. During the reading process, they read by themselves or discussed with their group partners if they encountered aspects that they did not understand. Students were not required to keep a response journal, but they were encouraged to write down their questions and responses on the margin of the text. The written notes could be used in their group discussion. When all group members finished reading, they proceeded to conduct a peer-led discussion about the text. During the discussion, group members played the assigned roles of discussion director, literary luminary, illustrator, and connector. The teacher neither provided discussion questions for students, nor intervened in the group discussion. The interpretive authority belonged solely to students.

\subsubsection{Instructional Conversations}

The instructional conversation approach included both instructional and conversational elements. A teacher explicitly explained the lesson text and directly taught reading skills. In addition, the teacher guided students to understand the content of the lesson through general comprehension questions about the text. The lesson instruction was followed by group discussions which were led by the teacher. The teacher provided an initiating question to start the discussion. These initiating questions were usually open-ended, concerning controversial issues in a text segment. Commenting upon student discussions, the teacher offered a follow-up question to prompt further discussions. The uptake question directed student attention to clarify the ambiguities from that portion of the text.

\subsubsection{Basal Comprehension Approach}

In basal comprehension instruction, lesson plans were primarily based on the instructional suggestions in the teacher's edition of the basal reader used in the participating classroom. The lesson was mainly conducted through an Initiate-Respond-Evaluate (IRE) pattern (Applebee, Langer, Nystrand, \& Gamoran, 2003; Mehan, 1978; Sinclair \& Coulthard, 1975). That is, while providing instruction of the text, a teacher posed the basal questions to the whole class, accepted short, literal responses from students, and then went on. The basal instruction focused student attention on comprehending the content of the text. It also emphasized post-reading exercises on vocabulary, grammar, sentence patterns, and reading comprehension.

\subsection{Participants}

\subsubsection{Students}

Student participants $(N=160)$ were all non-English-major college freshmen attending a public university on the eastern coast of Taiwan. They took regular Freshman English as a required course. To the best of our knowledge, the students' EFL reading education had been the commercial basal programs offered in senior high school.

Student participants with the same level of English language proficiency were selected from the study pool, based on their English scores $(M=60)$ on the 2010 Taiwan College Entrance Examination, and then randomly assigned to the control and experimental approaches. In order to determine the comparability of the control and experimental groups, the Intermediate-Level General English Proficiency Test (GEPT) was administered to these 160 student participants. ${ }^{1}$ The reading scores by approach are shown in Table 1 . The $F$ test was conducted for the GEPT scores. No significant differences between the control and experimental approaches were found: $F=$ 
$0.870, p>.05$.

Table 1. Means $(S D)$ and ANOVA result for GEPT by students in four approaches

\begin{tabular}{lllll}
\hline Approach & $n$ & $M(S D)$ & $F$ & $p$ \\
\hline Basal & 40 & $28.05(1.91)$ & .870 & .458 \\
Book Club & 40 & $27.78(1.87)$ & & \\
Literature Circles & 40 & $27.63(1.66)$ & & \\
Instructional Conversations & 40 & $28.23(1.86)$ & & \\
\hline
\end{tabular}

Note. Maximum Score $=40 \mathrm{pts}$

\subsubsection{Teachers}

The study invited four instructors to teach the control and experimental classes. The teachers received a three-day initial training, in which the teachers learned the theory and practice of each approach, and discussed lesson scripts with the principal investigator.

\subsection{Measures}

A variety of author-created measures were used to evaluate the teaching effects of the four instructional approaches.

\subsubsection{Lesson-Text Comprehension Assessments}

The lesson-text comprehension assessments aimed to measure the students' progress in understanding the assigned reading. They included Factual Comprehension and Interpretive Comprehension Tests, whose sample questions are provided in Appendices B-1 and B-2. As the previous tests might not fully capture student growth in higher order comprehension, essays were used to fill the assessment gaps. Students were asked to write Theme Explanation and Theme Exemplification Essays, as presented in Appendices C-1 and C-2. The essays were scored as illustration and evidence of students' high-level thinking abilities.

\subsubsection{Beyond-Lesson-Text Comprehension Assessments}

The purpose of the beyond-lesson-text comprehension test was to assess how well students could maintain and transfer the reading skills acquired from their lessons to after-class reading materials. See Appendix D for the sample comprehension questions on the nonlesson text.

The three experimental approaches provided intensive practice of group discussion during which time students applied critical and analytical skills to text discussion. Given this instructional activity, the students in the experimental classes were expected to produce better performance of acquiring and applying comprehension skills to the beyond-lesson-text reading materials than the students in the control group did.

\subsubsection{Scoring Tests and Grading Essays}

The multiple-choice items of the comprehension assessments were automatically scored by computer. The written portions of the interpretive comprehension test were scored manually by an English instructor who was not involved in the study but trained using answer keys and scoring rubrics. The scorer was completely blind to student identity and instructional condition, no matter whether the tests were administered as a pre- or post-measure. The reliability of the interpretive comprehension test scores was checked using the same answer key and reviewing random sample of 87 tests (30\% of 290 in total). For the interpretive comprehension questions, I concurred with the instructor's score on $89 \%$ of the items (619 of 696). In the cases of non-agreement, scores were no more than 1 point apart.

Two English instructors who were not involved in the current study graded all of the theme-related essays on a 1 to 4 scale. In cases of disagreement, I made the final decision regarding which of the scores would be granted to the essay. For the theme explanation essay, accurate agreement between the independent scorers was $88 \%$ ( 255 of 290 ); another $12 \%$ of papers ( 35 of 290 ) were 1 point apart. For theme exemplification, exact agreement between independent scorers was $90 \%$, while $10 \%$ were 1 point apart.

\subsection{Procedures}

The data presented and discussed in this article are collected by observing the following procedures. 


\subsubsection{Teacher Training}

Prior to implementation of the instructional approaches, the participating teacher attended a three-day workshop. The principal investigator introduced a general overview of the study's purpose, and then the teachers received intensive training in each approach: Book Club, Literature Circles, Instructional Conversations, and Basal Comprehension. The scripted lessons were reviewed, discussed, and demonstrated. Finally, the teachers were randomly assigned to the four instructional conditions.

\subsubsection{Student Preparation}

This study lasted for one autumn semester. The semester included five teaching units; each teaching unit consisted of one lesson text and two 50-minute lessons over three consecutive weeks. Through the initial four teaching units, students adapted themselves to the experimental approaches.

\subsubsection{Implementation of Lessons and Assessments}

The four instructional approaches were implemented in the four Freshman English classrooms. The instruction began in the middle of September and ended the following January. Every lesson was observed and videotaped by the research team. During the observations, the researcher carefully compared the lesson script to the classroom implementation. In case the classroom teachers made slight deviations from the script, the researcher gave rectifying feedback to the teachers after class and then continued monitoring whether the lesson was being conducted with a high degree of fidelity.

This study used a pretest/posttest $1 \times 4$ design to evaluate and compare the effects of the experimental approaches on students' high-level comprehension of text. As detailed in Table 2, the data were collected in three phases during the fifth teaching unit.

Table 2. Study procedures

\begin{tabular}{|c|c|c|c|c|}
\hline \multicolumn{5}{|c|}{ Phase 1: Pretest and whole class preparatory activities } \\
\hline Week & \multicolumn{4}{|c|}{ 1. Students take pre-essays on theme: Explanation \& Exemplification. } \\
\hline 1 & \multicolumn{4}{|c|}{ 2. An instructor offers a brief introduction to the story to be read. } \\
\hline & \multicolumn{4}{|c|}{ 3. Students read the entire story independently. } \\
\hline & \multicolumn{4}{|c|}{ 4. Students take a pre-comprehension test: Factual \& Interpretive Comprehension. } \\
\hline \multicolumn{5}{|c|}{ Phase 2: Experimental treatments } \\
\hline Week & Basal (control) & Book Club & Literature Circles & $\begin{array}{l}\text { Instructional } \\
\text { Conversations }\end{array}$ \\
\hline 2 & & $\begin{array}{l}\text { Response journal } \# 1 \text {, } \\
\text { book club meeting } \# 1 \text {, } \\
\& \text { whole class } \\
\text { discussion }\end{array}$ & Group discussion \#1 & $\begin{array}{l}\text { Instructional } \\
\text { conversation } \# 1\end{array}$ \\
\hline 3 & & $\begin{array}{l}\text { Response journal } \# 2 \text {, } \\
\text { book club meeting } \# 2 \text {, } \\
\& \text { whole class } \\
\text { discussion }\end{array}$ & Group discussion \#2 & $\begin{array}{l}\text { Instructional } \\
\text { conversation } \# 2\end{array}$ \\
\hline 4 & & $\begin{array}{l}\text { Response journal \#3, } \\
\text { book club meeting \#3, } \\
\& \quad \text { whole-class } \\
\text { discussion }\end{array}$ & Group discussion \#3 & $\begin{array}{l}\text { Instructional } \\
\text { conversation \#3 }\end{array}$ \\
\hline \multicolumn{5}{|c|}{ Phase 3: Post tests } \\
\hline Week & \multicolumn{4}{|c|}{ 1. Students take post-comprehension test: Factual \& Interpretive Comprehension. } \\
\hline 5 & \multicolumn{4}{|c|}{ 2. Students take post-essays on theme: Explanation \& Exemplification. } \\
\hline & \multicolumn{4}{|c|}{ 3. Students take a Beyond-Lesson-Text Comprehension Test. } \\
\hline
\end{tabular}

Phase 1 consisted of pretesting and whole-class preparatory activities. Students were first asked to write essays on what they thought about a story's theme (e.g., courage). Then the teachers introduced the story "A Day's Wait" with a prepared synopsis. Afterwards, students read the story independently within 50 minutes. Finally, 
students took a comprehension pretest on the story.

Phase 2 comprised the conduct of the teaching unit under experimental conditions. It commenced the week after the pretest and lasted three weeks. Each week, the teachers conducted two consecutive 50-minute English lessons. Table 2 outlines the discussion activities of each instructional condition. Students in the basal approach received teacher-directed instruction without participating in small group discussions.

Phase 3 included post-testing. In Week 5, the comprehension test was administered to the whole class and theme-related essays were completed. All of the students took the same comprehension test and finished the same essays used for the pretest. Finally, the beyond-lesson-text comprehension test was administered to students.

\section{Results}

In the following subsections, the results corresponding respectively to the research questions are presented. During the course of the research, some student participants (five basal-lesson students, three Book Club students, five Literature Circles students and two Instructional Conversations students) were dismissed from the study because of their repeated absences or their withdrawal from the course for unknown reasons. These subjects were excluded from the data analysis. The rest of the students were used as the unit of the analysis and the collected comprehension scores were analyzed with one-way analysis of variance (ANOVA) and with the Scheffe test run for determining post-hoc differences. The essay scores were analyzed with the Chi-Square test.

\subsection{Research Question 1: Impact on High-Level Comprehension of Lesson Texts}

To explore the impact of discussion-based approaches on students' performance of high-level reading comprehension, two types of comprehension assessments were used: lesson-text comprehension and beyond-lesson-text comprehension measures were used.

Four comprehension assessments were used for lesson texts: Factual Comprehension Test, Interpretive Comprehension Test, Theme Explanation Essay, and Theme Exemplification Essay. Mean scores for these assessments are presented in Tables 3, 4, 5, and 6 .

Table 3. Mean (SD) scores and analysis of variance results of post-treatment factual comprehension test and interpretive comprehension test by approach

\begin{tabular}{llllllll}
\hline & Basal & Book Club & Literature Circles & $\begin{array}{l}\text { Instructional } \\
\text { Conversations }\end{array}$ & \\
\hline Participant & $(n=35)$ & $(n=37)$ & $(n=35)$ & $(n=38)$ & & \\
Score type & $M(S D)$ & $M(S D)$ & $M(S D)$ & $M(S D)$ & $F$ & $p$ \\
$\begin{array}{l}\text { Factual } \\
\text { comprehension }\end{array}$ & $18.63(2.05)$ & $19.14(2.35)$ & $19.00(2.20)$ & $18.42(2.25)$ & .82 & .486 \\
$\begin{array}{l}\text { Interpretive } \\
\text { comprehension }\end{array}$ & $12.63(3.33)$ & $15.59(2.68)$ & $15.29(2.19)$ & $14.63(3.58)$ & 6.97 & .000 \\
\hline
\end{tabular}

Note. Maximum score $=26$ pts.

\subsubsection{Factual Comprehension Test}

As can be seen in Table 3, all four groups did moderately well on the Factual Comprehension Test. Analyses showed that there were no significant differences across approaches for the factual comprehension $(F=0.82 ; p$ $=.486$ ).

\subsubsection{Interpretive Comprehension Test}

As seen in Table 3, the ANOVA for the Interpretive Comprehension Test revealed a significant difference $(F=$ $6.97 ; p=.000$ ). Scheffe post-hoc comparison tests indicated that experimental lessons had a significantly higher score of interpretive comprehension than the control lesson did. The experimental lessons were not significantly different from one another. The results are presented in Table 4. 
Table 4. Scheffe post-hoc comparison for interpretive comprehension test

\begin{tabular}{lllll}
\hline Approach (I) & Approach (J) & Mean difference (I-J) & df & $p$ \\
\hline \multirow{3}{*}{ Basal } & Book Club & $-2.966^{*}$ & .709 & .001 \\
& Literature Circles & $-2.657^{*}$ & .718 & .004 \\
& Instructional Conversations & $-2.003^{*}$ & .704 & .048 \\
\hline \multirow{2}{*}{ Book Club } & Literature Circles & .309 & .709 & .979 \\
& Instructional Conversations & .963 & .694 & .589 \\
\hline
\end{tabular}

* The mean difference is significant at the .05 level.

\subsubsection{Theme Explanation Essay}

Analysis of data for theme explanation essay is presented in Table 5. It indicates that the number of the experimental-group students receiving a full score of 4 was significantly greater than that of the control group $\left(\chi^{2}\right.$ $=21.80 ; p=.010)$.

\subsubsection{Theme Exemplification Essay}

The scores of the approaches were also significantly different on theme exemplification. As presented in Table 6 , post-hoc analyses indicate that experimental approaches produced significantly greater numbers of students receiving a full score of 4 than did the control approach $\left(\chi^{2}=19.80 ; p=.019\right)$.

Table 5. Post-treatment theme explanation essay results

\begin{tabular}{llllllll}
\hline Approach & $n$ & Score 1 & Score 2 & Score 3 & Score 4 & $\chi^{2}$ & $p$ \\
\hline Basal & 35 & 11 & 15 & 4 & 5 & & \\
Book Club & $39.3 \%$ & $38.5 \%$ & $17.4 \%$ & $9.1 \%$ & & \\
& & 5 & 6 & 7 & 19 & 21.800 & .010 \\
Literature Circles & 35 & 6 & 6 & 9 & 14 & & \\
& & $21.4 \%$ & $15.4 \%$ & $39.1 \%$ & $25.5 \%$ & & \\
Instructional & 38 & 6 & 12 & 3 & 17 & & \\
Conversations & & $21.4 \%$ & $30.8 \%$ & $13.0 \%$ & $30.9 \%$ & & \\
\hline
\end{tabular}

Note. The data are the distribution of scores, ranging from 1 to 4 , students received on this assessment. Score 1 represents no clear concept of courage; Score 2, a materialistic concept of courage; Score 3, between materialistic and moralistic concepts of courage; Score 4, a moralistic concept of courage.

Table 6. Post-treatment theme exemplification essay results

\begin{tabular}{llllllll}
\hline Approach & $n$ & Score 1 & Score 2 & Score 3 & Score 4 & $\chi^{2}$ & $p$ \\
\hline Basal & 35 & 10 & 16 & 3 & 6 & & \\
Book Club & & $41.7 \%$ & $42.1 \%$ & $12.0 \%$ & $10.3 \%$ & & \\
& 37 & 4 & 7 & 8 & 18 & 19.806 & .019 \\
Literature Circles & 35 & 5 & 7 & 8 & 15 & & \\
& & $20.8 \%$ & $18.4 \%$ & $32.0 \%$ & $25.9 \%$ & & \\
Instructional & 38 & 5 & 8 & 6 & 19 & & \\
Conversations & & $20.8 \%$ & $21.1 \%$ & $24.0 \%$ & $32.8 \%$ & & \\
\hline
\end{tabular}

Note. The data are the distribution of scores, ranging from 1 to 4 , students received on this assessment. Score 1 represents no clear concept of courage; Score 2, a materialistic concept of courage; Score 3, between materialistic and moralistic concepts of courage; Score 4, a moralistic concept of courage. 


\subsection{Reach Question 2: Impact on Comprehension of Nonlesson Texts}

In addition to the lesson-text comprehension assessments, one assessment was independent of the lesson texts, in order to evaluate how well students maintained and applied the reading skills acquired in the study lessons. The assessment, which consisted of both factual and interpretive comprehension questions, had a total possible score of 26 points. The ANOVA revealed that there was a main effect of approach, $F(3,141)=5.03, p=.002$. Scheffe post-hoc tests on the scores indicated that the experimental groups significantly outperformed the control group, meaning that discussion-based approaches helped students transfer reading skills to their own reading more effectively than did the basal comprehension approach. However, the experimental approaches were not significantly different from one another. These results are presented in Tables 7 and 8.

Table 7. Mean (SD) scores and analysis of variance results of beyond-lesson-text comprehension test by approach

\begin{tabular}{lllllll}
\hline & Basal & Book Club & $\begin{array}{l}\text { Literature } \\
\text { Circles }\end{array}$ & $\begin{array}{l}\text { Instructional } \\
\text { Conversations }\end{array}$ & & \\
\hline Participant & $(n=35)$ & $(n=37)$ & $(n=35)$ & $(n=38)$ & & \\
Score type & $M(S D)$ & $M(S D)$ & $M(S D)$ & $M(S D)$ & $F$ & $p$ \\
$\begin{array}{l}\text { Beyond-Lesson-Text } \\
\text { comprehension }\end{array}$ & $18.17(2.78)$ & $17.32(2.21)$ & $17.06(2.89)$ & $16.92(2.49)$ & 5.03 & .002 \\
\hline
\end{tabular}

Note. Maximum score $=26$ pts.

Table 8. Scheffe post-hoc comparison for beyond-lesson-text comprehension test

\begin{tabular}{lllll}
\hline Approach (I) & Approach (J) & Mean difference (I-J) & df & $p$ \\
\hline \multirow{2}{*}{ Basal } & Book Club & $-2.153^{*}$ & .613 & .008 \\
& Literature Circles & $-1.886^{*}$ & .621 & .030 \\
\hline \multirow{2}{*}{ Book Club } & Instructional Conversations & $-1.750^{*}$ & .609 & .045 \\
\hline
\end{tabular}

* The mean difference is significant at the .05 level.

\section{Discussion}

The main purpose of the present study was to examine the hypothesis that engaging EFL students in text discussion promotes their high-level reading comprehension. I examined this hypothesis by investigating the effects of Book Club, Literature Circles, and Instructional Conversations, which were all discussion-based approaches to teaching students reading skills through small-group discussions. I subjugated my hypothesis to a rigorous experiment, focusing not only on students' lesson-text comprehension but also on their ability to understand beyond study lessons. The results of this study supported my contention that students who received discussion-centered instruction performed significantly better on higher order reading comprehension than did the control students.

\subsection{Factual Comprehension Test}

There were no significant differences between the control group (the basal comprehension approach) and the experimental groups (Book Club, Literature Circles, and Instructional Conversations) in regard to the literal understanding of text. This finding suggests that students in both the control and experimental conditions were doing moderately well (see Table 3). The result might be interpreted to indicate that the experimental approaches did not produce a learning advantage through regular practice of text-based discussion, in comparison with the basal comprehension approach. It should be noted, however, that the assessment itself might fail to reflect the learning advantage of the experimental lessons. The Factual Comprehension Test merely focused on the understanding and recalling of story details, which does not require much complex thinking. For the basic understanding of story facts, in-depth discussion about text may be less useful and helpful. 


\subsection{Interpretive Comprehension Test}

The experimental approaches did make a difference for the high-level thinking required by an interpretive comprehension test. The difference in interpretive comprehension of literary texts favored the experimental groups (see Tables 3 and 4). Interpretive comprehension certainly demands more sophisticated thinking than factual comprehension does. In meaning construction related to text, readers have to undertake multiple cognitive activities such as reading between the lines, citing evidence from the text, and integrating various viewpoints into a coherent whole. Indeed, an interpretative test requires students to apply a higher level of thinking to their reading. In contrast, factual comprehension simply requires understanding the text message and recollecting it from memory in order to answer questions.

Given the emphasis on meaning construction related to text through group discussion, one would assume that the treatment students definitely had an advantage on the interpretive comprehension assessment. The discussion-centered approaches, i.e., Book Club, Literature Circles, and Instructional Conversations, encouraged and prompted students to talk and think about text meaning more than the basal comprehension approach did. The more students discussed text content, the more text ideas they acquired to construct an interpretation. Indeed, students in the treatment group progressed significantly in their ability to comprehend and interpret the text, as compared with their control group counterparts.

\subsection{Theme-Related Essays}

As for the Theme Explanation and Exemplification Essays, the discussion-based approaches did prove an advantage over the basal-comprehension instruction. Significant differences were found for the essay scores (see Tables 5 and 6). These essay tests were productive measures that captured a higher level of comprehension more efficaciously than multiple-choice tests did. Thus, these results are quite meaningful because the differences between the basal comprehension and discussion-based lessons are noteworthy under a stringent test.

Viewing the differences on the essay scores as the result of classroom discussion activities also makes sense because lesson discourse in the experimental approaches was more focused on the meanings of, and beyond, the text. Because of its full focus on important text ideas, discussion-based instruction may be more likely to support students in understanding a story's main ideas and building a valid interpretation. Therefore, it might not be so difficult for the students in the experimental groups to elaborate on a story's theme and provide a concrete example to illustrate the theme. The available evidence suggests that the students who received Book Club, Literature Circles, and Instructional Conversations did benefit from discussions about text in regard to promoting their high-level comprehension. Generally speaking, text-based discussions encouraged students to recall what they had learned from the text, and incorporate the preliminary understanding into a sound holistic interpretation, as attested to in their essays and interpretive comprehension test.

\subsection{Beyond-Lesson-Text Comprehension}

The beyond-lesson-text reading assessment, in which students read a short text and answered both factual and interpretative comprehension questions, was intended to measure the maintaining and transferring of reading strategies which students might have acquired from the instructional approach used in their classroom. It was anticipated that the experimental approaches would show their advantage over the basal-comprehension approach. The underlying rationale for the experimental instruction is that text-based discussion is considered to be highly beneficial to students' development of reading comprehension. The Book Club, Literature Circles, and Instructional Conversations approaches could be advantageous for students since small-group discussions stimulate the comprehension process. Engagement in such discussions may promote the development of comprehension skills that students incorporate into their broad repertoire. Students are expected to use comprehension strategies in target texts, and then to apply them to other texts on their own.

The result of the beyond-lesson-text comprehension task in the current study showed significant differences between the approaches. The difference in the scores favored the experimental groups, reaching the $p<.05$ level of significance (see Table 7). This result suggests that the test did capture the potential gains in comprehension ability students sustained after the immediate treatment period, and supports the conclusion that the experimental approaches had positive effects. The conclusion of this study then is that students in the experimental groups were successful in retaining and applying enhanced reading skills.

In considering what to make of the beyond-lesson-text comprehension result, two observable facts are noteworthy. First, there was a small decrease in this measurement, in comparison with the lesson-text comprehension, regardless of instructional approach. The decrease in scores suggests the tendency of mean regression in terms of students' learning attainment. Without exacerbating the novelty effect, this assessment 
reflects the actual level of students' reading proficiency. Second, the scores were moderate overall across approaches. The scores themselves indicate that the test was quite difficult for most of the students. This test may be valuable, but revision is necessary before it could be an efficient measurement tool in further studies.

\subsection{Limitations and Implications}

This study is not meant to be definitive in regard to applying text-based discussion in reading instruction to promote EFL students' high-level comprehension. Book Club, Literature Circles, and Instructional Conversations are some typical examples of what a discussion-based approach might look like. There might be other choices concerning the way discussions are conducted, the genre used in discussion, and the discussion strategies utilized in the lessons.

A question that remains unanswered is whether students' English language proficiency, study motivation, and learning style might affect the results. Further research could provide insights if they are designed to investigate the interactions among these factors. One prominent limitation of this study is that the experimental approaches adapted were originally designed for English L1 students. Although the selection of these instructional approaches can be justified on the grounds of derivation from prior studies highly recognized within the reading research community, the EFL learning situation is significantly different from the L1 context. It remains to be explored whether some pertinent instructional characteristics which belong solely to English language learners might not be inspected.

Another limitation is caused by certain students who were excluded from the data analysis. Fifteen students $(9 \%$ of the classes' enrollment) were expelled from the research because they were excessively absent from class or had dropped the course for personal reasons. Therefore, the research results can only be generalized to the students who attended class regularly. Likewise, this study which was situated in four EFL classrooms investigated the learning experiences of 145 students over one semester. It is almost impracticable to claim that the findings can be generalized to other English language learners under other circumstances.

Also, four different instructors executed the four teaching approaches respectively for the purpose of comparison; although teachers are only the agents of prepared instruction, teacher variation may still play an important role. While the instructional activities per se may have led to students' comprehension gains, the teacher effect cannot be completely ignored when the various measure outcomes of different teaching approaches are compared.

The other limitation to the study is the timing of implementing dependent measures; logically, since this has an influence over the effects that are presented, it is consequently almost impossible to circumvent the limits to the number of potential effects to measure. Specific to the present study, the measurement of beyond-lesson-text comprehension was limited because it was obtained immediately after the instructional treatment. Certainly, it would be advantageous to measure any longitudinal effect. For instance, it would be desirable to measure what students could perform if given a narrative text to read on their own, following some prolonged lapse of time after instruction.

With these limitations in mind, I regard the study as carrying implications that are meaningful to the field of L2 reading instruction. While the differences that favor the discussion-based approaches were far from large, they showed a consistent pattern on several measurements. This study has the following implications for pedagogy.

First, the findings could inspire teacher confidence in employing discussion as a teaching method in L2 reading instruction to enhance students' comprehension. Many ESL teachers intuitively harbor considerable doubts concerning English language learners' ability to conduct meaningful small-group discussions on text simply because of their limited language proficiency. Yet, by allowing them to talk in their mother tongue as well as in English, EFL students can be trained to think about the text in the same high-level way as native English speakers. In the present study, students learned to work with their peers in cooperative groups to comprehend, criticize, and evaluate the text. Quality discussions on literature are not exclusive to English L1 students; with the support and instruction provided within the Book Club, Literature Circles, and Instructional Conversations, EFL students can do it, too.

Second, an issue for practice is the decision about whether to use the basal-comprehension approach or the discussion-based methods. The results of this study support the recommendation that teachers should use group discussion as an approach for practice, as it could generate considerable positive effects. Third, if teachers cannot change the mandatory basal curriculum, they can implement Book Club, Literature Circles, or Instructional Conversations as part of their curriculum to help enhance EFL students' reading comprehension. At least some of the instructional time should be spent on discussion; a teacher's lecturing can alternate with peer-led discussions.

The classroom talk approaches are beneficial for English language learners in regard to high-level reading 
comprehension. The value of discussion practices includes enabling EFL students with poor reading skills to have sufficient time to process the text, providing a visible demonstration of the understanding process, engaging students in constructing text meaning through collaborative discussion, and letting students have access to their peers' thinking. In the process of building comprehension, students can also have support from their teacher to solve problems. The teacher can also benefit from this teaching format, for example, in being able to monitor problems as they occur, and observe what common confusion and difficulty students might encounter. By gaining an immediate understanding of students' problems, the teacher will better know how to effectively intervene to assist students.

Further research is needed to search for efficient EFL reading instruction that can produce much more satisfactory effects than those documented in the current study. Despite the finding that the experimental approaches produced positive effects on higher order comprehension of text, students' total reading performance did not reach a superior level. The average factual comprehension for the experimental groups was only $75 \%$, and the average interpretive comprehension for these same groups was merely $60 \%$. On average, no more than $58 \%$ of the participants in the experimental groups were capable of explaining a story's theme correctly, and barely 59\% were able to provide an appropriate example to illustrate the theme clearly. Indeed, the fact that the discussion-based approaches appear to elevate EFL college students' literacy attainment did encourage me to proceed in the direction of discussion-centered instruction. More investigation, however, needs to be done to meet the educational standards that demand EFL students reach a higher level of learning achievement.

\section{Acknowledgements}

I cordially acknowledge the National Science Council, Taiwan for its support of the research reported here through Grant NSC 99-2410-H-143-012. The opinions expressed here are those of the author and do not represent the views of the Taiwan National Science Council.

\section{References}

Anderson, R. C., Chinn, C., Waggoner, M., \& Nguyen, K. (1998). Intellectually stimulating story discussions. In J. Osborn, \& F. Lehr (Eds.), Literacy for all: Issues in teaching and learning (pp. 170-186). New York: Guilford.

Applebee, A. N., Langer, J. A., Nystrand, M., \& Gamoran, A. (2003). Discussion-based approaches to developing understanding: Classroom instruction and student performance in middle and high school $\begin{array}{llll}\text { English. American Educational Research Journal, } & \text { 40(3), }\end{array}$ http://dx.doi.org/10.3102/00028312040003685

Beck, I. L., McKeown, M. G., Hamilton, R. L., \& Kucan, L. (1997). Questioning the author: An approach for enhancing student engagement with text. Newark, NJ: International Reading Association.

Beck, I. L., McKeown, M. G., Sandora, C., Kucan, L., \& Worthy, J. (1996). Questioning the Author: A yearlong classroom implementation to engage students with text. The Elementary School Journal, 96(4), 385-414. http://dx.doi.org/10.1086/461835

Billings, L., \& Fitzgerald, J. (2002). Dialogic discussion and the Paideia Seminar. American Educational Research Journal, 39(4), 907-941. http://dx.doi.org/10.3102/00028312039004905

Bransford, J. D., Brown, A. L., \& Cooking, R. R. (1999). How people learn: Brain, mind, experience, and school. Washington, DC: National Academy Press.

Brock, C. H., McVee, M. B., Shojgreen-Downer, A. M., \& Duenas, L. F. (1998). No habla ingles: Exploring a bilingual child's literacy learning opportunities in a predominantly English-speaking classroom. Bilingual Research Journal, 22(2-4), 175-200. http://dx.doi.org/10.1080/15235882.1998.10162721

Carrison, C., \& Ernst-Slavit, G. (2005). From silence to a whisper to active participation: Using literature circles with ELL students. Reading Horizon, 46(2), 93-113.

Cazden, C. B. (2001). Classroom discourse: The language of teaching and learning (2nd ed.). Portsmouth, NH: Heinemann.

Chang-Wells, G., \& Wells, G. (1993). Dynamics of discourse: Literacy and the construction of knowledge. In E. Forman, N. Minick, \& C. A. Stone (Eds.), Contexts for learning: Sociocultural dynamics in children's development (pp. 58-90). New York: Oxford University Press.

Chinn, C. A., O’Donnell, A. M., \& Jinks, T. S. (2000). The structure of discourse in collaborative learning. Journal of Experimental Education, 69(1), 77-97. http://dx.doi.org/10.1080/00220970009600650 
Echevarria, J., \& McDonough, R. (1995). An alternative reading approach: Instructional conversations in a bilingual special education setting. Learning Disabilities Research \& Practice, 10(2), 108-119.

Eeds, M., \& Wells, D. (1989). Grand Conversations: An exploration of meaning construction in literature study groups. Research in the Teaching of English, 23(1), 4-29.

Farris, P. J., Nelson, P. A., \& L'Allier, S. (2007). Using literature circles with English language learners at the middle level. Middle School Journal, 38(4), 38-42.

Goatley, V. J., Brock, C. H., \& Raphael, T. E. (1995). Diverse learners participating in regular education "book clubs". Reading Research Quarterly, 30(3), 352-380. http://dx.doi.org/10.2307/747621

Goldenberg, C. (1993). Instructional conversations: Promoting comprehension through discussion. The Reading Teacher, 46(4), 316-326.

Great Books Foundation. (1987). An introduction to shared inquiry. Chicago: Author.

Kim, M. (2004). Literature discussions in adult L2 Learning. Language and Education, 18(2), 145-166. http://dx.doi.org/10.1080/09500780408666872

Kong, A., \& Fitch, E. (2002). Using Book Club to engage culturally and linguistically diverse learners in reading, writing, and talking about books. The Reading Teacher, 56(4), 352-362.

Martinez-Roldan, C. M., \& Lopez-Robertson, J. M. (1999). Initiating literature circles in a first-grade bilingual classroom. The Reading Teacher, 53(4), 270-281.

McCann, T. M., Johannessen, L. R., Kahn, E., \& Flanagan, J. M. (2006). Talking in class: Using discussion to enhance teaching and learning. Urbana, IL: National Council of Teachers of English.

Mehan, H. (1978). Structuring school structure. Harvard Educational Review, 48(1), 32-64.

Mercer, N. (2000). Words and minds: How we use language to think together. London: Routledge.

Murphy, P. K., Wilkinson, I. A. G., Soter, A. O., Hennessey, M. N., \& Alexander, J. F. (2009). Examining the effects of classroom discussion on students' high-level comprehension of text: A meta-analysis. Journal of Educational Psychology, 101, 740-764.

Nystrand, M. (1997). Dialogical instruction: When recitation becomes conversation. In M. Nystrand, A. Gamoran, R. Kachur, \& C. Prendergast (Eds.), Opening dialogue: Understanding the dynamics of language and learning in the English classroom (pp. 1-29). New York: Teachers College Press.

Nystrand, M., Wu, L. L., Gamoran, A., Zeiser, S., \& Long, D. A. (2003). Questions in time: Investigating the structure and dynamics of unfolding classroom discourse. Discourse Processes, 35(2), 135-198. http://dx.doi.org/10.1207/S15326950DP3502_3

Olezza, A. M. (1999). An examination of effective instructional and social interactions to learn English as a second language in a bilingual setting. Unpublished doctoral dissertation, University of Connecticut, Connecticut.

Peralta-Nash, C., \& Dutch, J. A. (2000). Literature Circles: Creating an environment for choice. Primary Voice $K-6,8(4), 29-37$.

Perez, B. (1996). Instructional conversations as opportunities for English Language acquisition for culturally and linguistically diverse students. Language Arts, 73, 173-181.

RAND Reading Study Group. (2002). Reading for understanding: Toward an R\&D program in reading comprehension. Santa Monica, CA: Rand.

Raphael, T. E., \& Brock, C. H. (1993). Mei: Learning the literacy culture in an urban elementary school. In D. Leu, \& C. Kinzer (Eds.), Examining central issues in literacy research, theory, and practice (pp. 179-188). Chicago: National Reading Council.

Raphael, T. E., \& McMahon, S. I. (1994). Book Club: An alternative framework for reading instruction. The Reading Teacher, 48(2), 102-116. http://dx.doi.org/10.1598/RT.48.2.1

Saunders, W. M., \& Goldenberg, C. (1999). Effects of instructional conversations and literature logs on limitedand fluent-English-proficient students' story comprehension and thematic understanding. The Elementary School Journal, 99(4), 277-301. http://dx.doi.org/10.1086/461927

Saunders, W. M., Patthey-Chavez, G., \& Goldenberg, C. (1997). Reflections on the relationship between language, curriculum content, and instruction. Language, Culture and Curriculum, 10(1), 30-51. 
Sharp, A. M. (1985). Philosophy for children and the development of ethical values. Early Child Development and Care, 197, 45-55. http://dx.doi.org/10.1080/0300443951070106

Short, K. G., \& Pierce, K. M. (1990). Talking about books: Creating literature communities. Portsmouth, NH: Heinemann.

Sinclair, J., \& Coulthard, M. (1975). Toward an analysis of discourse. Oxford, United Kingdom: Oxford University Press.

Soter, A. O., Wilkinson, I. A. G., Connors, S. P., Murphy, P. K., \& Shen, V. F. Y. (2010). Deconstructing "Aesthetic Response" in small-group discussions about literature: A possible solution to the "Aesthetic Response" dilemma. English Education, 42(2), 204-225.

Soter, A. O., Wilkinson, I. A. G., Murphy, P. K., Rudge, L., Reninger, K., \& Edwards, M. (2008). What the discourse tells us: Talk and indicators of high-level comprehension. International Journal of Educational Research, 47(6), 372-391. http://dx.doi.org/10.1016/j.ijer.2009.01.001

Todhunter, S. (2007). Instructional conversations in a high school Spanish class. Foreign Language Annals, 40(4), 604-621. http://dx.doi.org/10.1111/j.1944-9720.2007.tb02883.x

Waggoner, M. A., Chinn, C., Yi, H., \& Anderson, R. C. (1995). Collaborative reasoning stories. Language Arts, 72, 582-588.

Wegerif, R., Mercer, N., \& Dawes, L. (1999). From social interaction to individual reasoning: An empirical investigation of a possible socio-cultural model of cognitive development. Learning and Instruction, 9(6), 493-516.

Wilkinson, I. A. G., Soter, A. O., \& Murphy, P. K. (2010). Developing a model of Quality Talk about literary text. In M. G. McKeown, \& L. Kucan (Eds.), Bringing reading research to life (pp. 142-169). New York: Guilford Press.

\section{Note}

Note 1. The General English Proficiency Test (GEPT) is one of the most widely used language tests in Taiwan. GEPT was developed by the Language Training and Testing Center (LTTC) in Taiwan. This test is divided into five levels: Elementary, Intermediate, High-intermediate, Advanced, and Superior. At each level, the examination is composed of listening, reading, writing, and speaking sections.

\section{Appendices}

Appendix A - 1. Sample Lesson Plan for Book Club

Teaching Unit: Hemingway's A Day's Wait

Estimated Lesson Time: 6 hours

Student Objectives

Students will

1. answer literal and interpretive questions

2. keep a response journal that demonstrates an active transaction with the text

3. work in peer-led small groups to analyze, interpret, and criticize the text

4. acquire reading comprehension strategies

Instruction and Activities

Week 1

Stage 1 - Teacher-directed whole class instruction (30 minutes)

1. Explain new vocabulary and complex sentences

1.1 "Schatz" is a German term roughly meaning "darling."

1.2 "One was to bring down the fever, another a purgative, the third to overcome an acid condition" should be read as "one was to bring down the fever, another was a purgative, and the third was to overcome an acid 
condition." Here the verb and conjunction are left out for narrative brevity.

1.3 Distinguish the usage of that (i.e., relative pronoun used in the defining relative clause) and so that (i.e., conjunction) in this long sentence, "it was a bright, cold day, the ground covered with a sleet that had frozen so that it seemed as if all the bare trees, the bushes, the cut brush and all the grass and the bare ground had been varnished with ice."

1.4 a light epidemic of flu: Flu had spread to several people in the community but not many

1.5 Irish setter: Type of dog with red hair; a hunting dog.

(Adapted from Danielson, Hayden, Hinze-Pocher \& Glicksberg, 1993)

2. Analyze literary elements

2.1 Literary characters

Recognize a character's specific characteristics and consider how those main personality traits contribute to an overall effect of characterization.

\subsection{Setting}

Help students to understand various dimensions of setting: "Setting as physical", "setting as temporal," and "setting as social and psychological" (Smith \& Wilhelm, 2010, p. 70).

3. Teach reading strategies

The teacher demonstrates reading strategies.

3.1 Monitoring comprehension

3.2 Context clues

3.3 Identifying main ideas

3.4 Identifying supporting ideas

Stage 2 - Students' independent reading (15 minutes)

Stage 3 - Response journal writing (10 minutes)

Stage 4 - Book Club discussion (30 minutes)

Students are divided into small groups to discuss the story.

Stage 5 - Community sharing (15 minutes)

Week 2

Appendix A - 2. Sample Lesson Plan for Literature Circles

Teaching Unit: Hemingway's A Day's Wait

Estimated Lesson Time: 6 hours

Student Objectives

Students will

1. answer literal and interpretive questions

2. work in peer-led small groups to analyze, interpret, and criticize the text

3. play various roles (e.g., Illustrator, Researcher, Connector, Summarizer) in group disucsion

4. acquire reading comprehension strategies

Instruction and Activities

Week 1

Stage 1 - Teacher-directed whole class instruction (30 minutes)

1. Explain new vocabulary and complex sentences

1.1 "Schatz" is a German term roughly meaning "darling."

1.2 "One was to bring down the fever, another a purgative, the third to overcome an acid condition" should be read as "one was to bring down the fever, another was a purgative, and the third was to overcome an acid condition." Here the verb and conjunction are left out for narrative brevity. 
1.3 Distinguish the usage of that (i.e., relative pronoun used in the defining relative clause) and so that (i.e., conjunction) in this long sentence, "it was a bright, cold day, the ground covered with a sleet that had frozen so that it seemed as if all the bare trees, the bushes, the cut brush and all the grass and the bare ground had been varnished with ice."

1.4 a light epidemic of flu: Flu had spread to several people in the community but not many

1.5 Irish setter: Type of dog with red hair; a hunting dog.

(Adapted from Danielson, Hayden, Hinze-Pocher \& Glicksberg, 1993)

2. Analyze literary elements

\subsection{Literary characters}

Recognize a character's specific characteristics and consider how those main personality traits contribute to an overall effect of characterization.

\subsection{Setting}

Help students to understand various dimensions of setting: "Setting as physical", "setting as temporal," and "setting as social and psychological" (Smith \& Wilhelm, 2010, p. 70).

3. Teach reading strategies

The teacher demonstrates reading strategies.

3.1 Monitoring comprehension

3.2 Context clues

3.3 Identifying main ideas

3.4 Identifying supporting ideas

Stage 2 - Students' independent reading (30 minutes)

Stage 3 - Literature Circles meeting (40 minutes)

Students are divided into small groups to discuss the story.

Week 2

Appendix A - 3. Sample Lesson Plan for Instructional Conversations

Teaching Unit: Hemingway's A Day's Wait

Estimated Lesson Time: 6 hours

Student Objectives

Students will

1. answer literal and interpretive questions

2. work in teacher-led small groups to analyze, interpret, and criticize the text

3. acquire reading comprehension strategies

Instruction and Activities

Week 1

Stage 1 - Reading instruction (50 minutes)

The teacher guides students to read the story.

1. Explain new vocabulary and complex sentences

1.1 "Schatz" is a German term roughly meaning "darling."

1.2 "One was to bring down the fever, another a purgative, the third to overcome an acid condition" should be read as "one was to bring down the fever, another was a purgative, and the third was to overcome an acid condition." Here the verb and conjunction are left out for narrative brevity.

1.3 Distinguish the usage of that (i.e., relative pronoun used in the defining relative clause) and so that (i.e., conjunction) in this long sentence, "it was a bright, cold day, the ground covered with a sleet that had frozen so that it seemed as if all the bare trees, the bushes, the cut brush and all the grass and the bare ground had been 


\section{varnished with ice."}

1.4 a light epidemic of flu: Flu had spread to several people in the community but not many

1.5 Irish setter: Type of dog with red hair; a hunting dog.

(Adapted from Danielson, Hayden, Hinze-Pocher \& Glicksberg, 1993)

2. Analyze literary elements

2.1 Literary characters

Recognize a character's specific characteristics and consider how those main personality traits contribute to an overall effect of characterization.

\subsection{Setting}

Help students to understand various dimensions of setting: "Setting as physical", "setting as temporal," and "setting as social and psychological" (Smith \& Wilhelm, 2010, p. 70).

3. Teach reading strategies

The teacher demonstrates reading strategies.

3.1 Monitoring comprehension

\subsection{Context clues}

\subsection{Identifying main ideas}

3.4 Identifying supporting ideas

4. Post comprehension prompts

The teacher reminds students to think back what they just read and raises questions for them to think more about the important ideas in the text. Call on more than one student to answer these questions.

4.1 What time of the day did the story start?

4.2 What did the doctor say and do?

4.3 How did the father respond to his son's illness?

4.4 How did the boy act and what were his symptoms?

Stage 2 - Instructional Conversations (50 minutes)

Students are divided into small groups to discuss the story. The teacher rotates among the groups, leading discussion about the text through posting comprehension questions and raising follow-up questions.

Week 2

Appendix A - 4. Lesson Plan for the Basal Comprehension Approach

Teaching Unit: Hemingway's A Day's Wait

Estimated Lesson Time: 6 hours

Student Objectives

Students will

1) learn new vocabulary, practice sentence patterns, and review grammar

2) acquire reading comprehension strategies

3) answer literal and interpretive questions

Instruction and Activities

Week 1

Stage 1 - Prereading preparation (15 minutes)

Teachers lead students to discuss the following questions:

1) What does a communication misunderstanding mean? Why does a misunderstanding happen?

2) What are some serious effects of misunderstanding in daily conversations?

3) Read the title of this short story. What do you think it means? 
Stage 2 - Reading instruction (50 minutes)

The teacher guides the students to read the story and makes sure all of the students understand the content.

1. Conduct guided reading

1.1 Read aloud the story from Lines 1-50

1.2 Translate difficult English sentences into Chinese

2. Explain new vocabulary and complex sentences

2.1 "Schatz" is a German term roughly meaning "darling."

2.2 "One was to bring down the fever, another a purgative, the third to overcome an acid condition" should be read as "one was to bring down the fever, another was a purgative, and the third was to overcome an acid condition." Here the verb and conjunction are left out for narrative brevity.

2.3 Distinguish the usage of that (i.e., relative pronoun used in the defining relative clause) and so that (i.e., conjunction) in this long sentence, "it was a bright, cold day, the ground covered with a sleet that had frozen so that it seemed as if all the bare trees, the bushes, the cut brush and all the grass and the bare ground had been varnished with ice."

2.4 a light epidemic of flu: Flu had spread to several people in the community but not many

2.5 Irish setter: Type of dog with red hair; a hunting dog.

(Adapted from Danielson, Hayden, Hinze-Pocher \& Glicksberg, 1993)

3. Analyze literary elements

3.1 Literary characters

Recognize a character's specific characteristics and consider how those main personality traits contribute to an overall effect of characterization.

\subsection{Setting}

Help students to understand various dimensions of setting: "Setting as physical", "setting as temporal," and "setting as social and psychological" (Smith \& Wilhelm, 2010, p. 70).

\section{Comprehension Check}

Ask students to answer the following comprehension questions:

1) What time of the day did the story start?

2) What did the doctor say and do?

3) How did the father respond to his son's illness?

4) How did the boy act and what were his symptoms?

5) Why didn't the boy want to go to sleep?

Stage 3 - Post-reading Instruction (35 minutes)

1. Review grammar

The teacher explains the text-related grammatical rules.

1.1 Linking verb: look (sound, appear) + adjective / NP

... I saw he looked ill.

... he was ... looking a very sick and miserable boy of nine years.

1.2 A present participial phrase replacing a subordinate clause

... after I gave him the prescribed capsules at eleven o'clock I went out for a while =

... after giving him the prescribed capsules at eleven o'clock I went out for a while

2. Teach reading strategies

The teacher demonstrates reading strategies.

2.1 Monitoring comprehension

2.2 Context clues 


\subsection{Identifying main ideas}

2.4 Identifying supporting ideas

Week 2

Appendix B - 1. Sample Factual Comprehension Questions on "A Day's Wait"

The test is composed of 26 questions about the factual details of the story. Answers are scored on a 2-point scale: 0 (incorrect), and 1 (correct). 26 points are possible.

\section{Comprehension Check}

True/False/Not Enough Information

1) The doctor leaves three different medicines in different size pills.

2) The father stays with the boy all day without going outside.

\section{Comprehension Questions}

Choose the best answer according to the reading.

1. What does the doctor say about the boy's health condition?
(A) The boy is hopeless.
(B) The boy is seriously ill.
(C) The boy needs special treatment.
(D) There is nothing to worry about.

2 . The only real danger the sick boy should avoid is
(A) pneumonia
(B) influenza (C) germs
(D) 104 degree fever

3. Who keeps a record of the boy's temperature?
(A) a servant (B) a doctor
(C) a nurse (D) his father

4. How does the boy react when his father is reading to him?
(A) He is very excited.
(B) He listens to the story carefully.
(C) He seems unable to maintain his focus on the story.
(D) He dislikes the story.

5. How does the boy respond when his father suggests that he try to sleep?
(A) He pleasantly accepts his suggestion.
(B) He prefers to stay awake.
(C) He soon falls asleep.
(D) He is so restless that he is unable to sleep.

6. The boy does not allow people to enter his room because
(A) he is shy.
(B) he enjoys being alone.
(C) he does not want people catch the flu he has.
(D) he is too tired to meet people.

7. Who tells the boy that people cannot survive with 45 degrees?
(A) His teacher
(B) His schoolmates in France
(C) His doctor
(D) His housemaid

8. Which one of the following statements is true about the boy's temperature?

(A) The boy was going to die because of high fever.

(B) The boy's temperature of 102 degrees did not cause his death. 
(C) The boy cannot survive a high fever of 39 degrees.

(D) The boy's temperature gradually rose to 104 degrees.

(Some of the test questions are adapted from Danielson, Hayden, Hinze-Pocher \& Glicksberg, 1993)

Appendix B - 2. Sample Interpretive Comprehension Questions on "A Day's Wait”

The test is composed of 18 questions calling for text-based interpretation of story events. Multiple-choice answers are scored on a 2-point scale: 0 (incorrect), and 1 (correct). Answers to essay questions are scored on a 3-point scale: 0 (incorrect), 1 (partially correct), and 2 (correct). 26 points are possible.

I. Multiple Choices

Choose the best answer according to the reading.

1. Which word would you use to describe the father?

(A) thoughtless (B) miserable (C) rigid (D) casual

2. "What's the matter, Schatz?"

"I've got a headache."

This dialogue suggests
(A) the boy's contact with European culture
(B) the boy's mental condition
(C) the father's social status
(D) the boy's loose relationship with his father

3. "I went up to him and found him in exactly the same position I had left him, ... staring still, as he had stared, at the foot of the bed." This passage indicates that
(A) the boy fell into a coma.
(B) the boy was very stubborn.
(C) the boy was thinking of his coming death so he held himself very tensely.
(D) the boy's body got stiff because of catching a cold.

4. What is the theme of "A Day's Wait"?

(A) One should communicate one's fears to others to avoid misunderstanding.

(B) To control one's emotions and fears when facing death is a mark of courage.

(C) Children cannot be expected to understand something as complex as death.

(D) Misunderstanding can occur even though a relationship is a close one.

\section{Short Answer}

Answer the questions briefly, in no more than two sentences or three.

1) Why does Schatz think that he is going to die?

2) How does Schatz behave when his father reads to him the first time? Why does the boy behave that way?

3) How does Schatz respond when his father suggests that he try to go to sleep? Why does the boy respond that way?

4) Why do you think Schatz chose not to reveal his fear to his father or to the doctor?

5) The father calls his son "Schatz," which is a German term of endearment roughly equivalent to "darling." The use of this term indicates that the family in the story knows European customs and culture. What is the significance of the boy's contact with European culture?

6) The misunderstanding between father and son is reflected in their conversation. Look at the italicized words in the following quotation. What is each character referring to? What is the misunderstanding?

"You don't have to stay here with me, Papa, if it bothers you."

"It doesn't bother me."

"No, I mean you don't have to stay if $i t$ 's going to bother you." 
(Some of the test questions are adapted from Danielson, Hayden, Hinze-Pocher \& Glicksberg, 1993)

Appendix C - 1. Theme Explanation Essay on "A Day's Wait"

Students are asked to explain the concept of courage, and essays will be graded as falling into one of 4 categories: 1-No clear concept of courage; 2-Materialistic (i.e., showing physical strength); 3-Materialistic/Moralistic (materialistic and moralistic interwoven); 4-Moralistic (i.e., overcoming oneself).

Question: Hemingway often thought of courage as a personal ability to be calm and controlled in the face of death. Elaborate on this theme.

Appendix C - 2. Theme Exemplification Essay on "A Day's Wait"

Students are asked to give an example of being courageous, and essays will be graded as falling into one of 4 categories: 1-No clear concept of courage; 2-Materialistic (i.e., showing physical strength); 3-Materialistic/Moralistic (materialistic and moralistic interwoven); 4-Moralistic (i.e., overcoming oneself).

Question: Describe a time when you or someone you know was definitely courageous. Give a specific example to illustrate true courage.

Appendix D. Sample Beyond-Lesson-Text Comprehension Assessment

The test comprises 26 multiple-choice questions. Half of the questions are about the factual details of the story, and the other questions call for text-based interpretations of story events. Answers are scored on a 2-point scale: 0 (incorrect), and 1 (correct). 26 points are possible in total.

Long Walk to Forever by Kurt Vonnegut, Jr.

Comprehension Questions

1. Where is Catharine's house located?

(A) downtown (B) inner city (C) business district (D) the suburbs

2. Which word wouldn't you use to describe Newt?

(A) shy (B) daring (C) romantic (D) All

3. Which word would you use to describe Catharine?

(A) reckless (B) blind (C) silly (D) romantic

4. Why does the author have Catharine open the door with a bride's magazine in her hand?

(A) To show how much she wants to be a bride

(B) To hint that she's getting married soon

(C) To indicate that she likes to daydream

(D) To explain why she's at home in the afternoon

5. In what way does Newt change most in the story?

(A) He overcomes his reservations about expressing his feelings for Catharine.

(B) He begins to realize that Catharine doesn't love him.

(C) He suddenly understands the consequences of going A.W.O.L.

(D) He admits that Henry Stewart Chasens is a better man than he is.

6. Newt repeats the statement "One foot in front of the other - through leaves, over bridges" throughout the story. What does his repetition of this phrase suggest?
(A) Newt's determination
(B) Catharine's shyness
(C) Newt's love of nature
(D) Catharine's anger

7. "I want to go for a walk," he said. She wrung her hands in sisterly anguish. "Oh, Newt--you're fooling me about being A.W.O.L.," she said.

Newt imitated a police siren softly, and raised his eyebrows. 
What do you think Newt's imitation of a police siren refers to?

(A) The risk that Newt has taken to see Catharine

(B) The sorrow Catharine feels for getting Newt into trouble

(C) The humor of Newt's predicament

(D) The confusion Catharine feels about marriage

8. Which of the following statements tell readers about the relationship between Newt and Catharine?
(A) They had grown up next door to each other.
(B) She wrung her hands in sisterly anguish.
(C) There had always been playful, comfortable warmth between them.
(D) All

9. Newt yawned.

The bees were humming in the trees, and Catharine almost fell asleep. When she opened her eyes she saw that Newt really was asleep.

Why does Newt fall asleep?

(A) He feels very bored with Catherine's speech.

(B) He feels tired after walking several hours to visit Catherine.

(C) He feels quite disappointed at Catherine's response to his proposal.

(D) He simply pretends to fall into sleep to fool Catherine.

10. Bells rang in the tower of the school for the blind nearby.

"School for the blind," said Newt.

"School for the blind," said Catharine.

The author keeps mentioning the "School for the blind." What do you think this might symbolize?
(A) Love is not necessarily blind.
(B) Don't be blind to one's true feelings.
(C) Be true to one's love.
(D) All

(Some of the test questions are adapted from Danielson, Hayden, Hinze-Pocher \& Glicksberg, 1993)

\section{Copyrights}

Copyright for this article is retained by the author(s), with first publication rights granted to the journal.

This is an open-access article distributed under the terms and conditions of the Creative Commons Attribution license (http://creativecommons.org/licenses/by/3.0/). 